\title{
A Facile Polyvinylpyrrolidone Assisted Solvothermal Synthesis of Zinc Oxide Nanowires and Nanoparticles and Their Influence on the Photovoltaic Performance of Dye Sensitized Solar Cell
}

\author{
Subramania Angaiah, ${ }^{1 *}$ Subasri Arunachalam, ${ }^{1,2}$ Vignesh Murugadoss ${ }^{1}$ and G. Vijayakumar ${ }^{3}$
}

\begin{abstract}
A facile polyvinylpyrrolidone (PVP) assisted solvothermal method was adopted to synthesis Zinc Oxide (ZnO) nanostructures. PVP was used as a capping agent as well as a nanoreactor to fabricate $\mathrm{ZnO}$ nanoparticles and $\mathrm{ZnO}$ nanowires by solvothermal reaction of zinc acetate in polyol medium. The influence of $\mathrm{Zn}$ (II)/PVP molar ratio on the size and morphology of $\mathrm{ZnO}$ was also investigated. The change in $\mathrm{ZnO}$ morphology from well-defined spherical nanoparticles to 1D-nanowire assembly upon varying Zn (II)/PVP molar ratio was observed by using SEM and TEM studies. 1D-ZnO nanowires based DSSC showed enhanced photovoltaic performance due to the absence of electron hopping that limited the electron transport in $\mathrm{ZnO}$ nanoparticles. The DSSC fabricated using $\mathrm{ZnO}$ nanowires as photoanode exhibited higher power conversion efficiency (PCE) of $1.81 \%$ than that fabricated using $\mathrm{ZnO}$ nanoparticles $(1.13 \%)$ as photoanode.
\end{abstract}

Keywords: Wurtzite ZnO; ZnO Nanoparticles; ZnO Nanowires; Solvothermal synthesis; Polyvinyl pyrrolidone

Received 25 January 2019, Accepted 14 April 2019

DOI: $10.30919 / \mathrm{esee} 8 \mathrm{c} 280$

\section{Introduction}

Recent research activities in the field of the dye-sensitized solar cell (DSSC) have drawn great interest in improving its performance. ${ }^{1-5}$ Being a crucial component, the photoanode material has a governing effect on overall photo-conversion efficiency of DSSC. ${ }^{6}$ Since, the first report by O'Regan and Grátzel on mesoporous $\mathrm{TiO}_{2}$ based DSSC, many other semiconductors such as $\mathrm{ZnO}$ and $\mathrm{SnO}_{2}$ have also been investigated in place of $\mathrm{TiO}_{2}$ for DSSC. . $^{7-11}$

$\mathrm{ZnO}$ possess high anisotropic growth compared to $\mathrm{TiO}_{2}$ along with good intrinsic electrical and optical properties, which helps to achieve high electron mobility, high electron diffusion coefficient and easy separation of photogenerated electrons. ${ }^{12,13}$ However, $\mathrm{TiO}_{2}$ based perovskite sensitized solar cell is still maintaining the record of the best photoconversion efficiency, which has now risen to $15.4 \% .{ }^{14,15}$ Despite, the higher electron mobility of $\mathrm{ZnO}$, DSSC comprised of $\mathrm{ZnO}$ nanoparticles show lower photoconversion efficiency than that of DSSC comprised of $\mathrm{TiO}_{2}$. Research efforts have been made to improve the performance of $\mathrm{ZnO}$ to use as DSSC photoanode. ${ }^{16-20}$ It is evident from the studies that the interdependence of electron transport $\left(\tau_{\mathrm{d}}\right)$ and electron lifetime $\left(\tau_{\mathrm{n}}\right)$ is the reason for the poor efficiency of $\mathrm{ZnO}$

${ }^{1}$ Electro-Materials Research Laboratory, Centre for Nanoscience and Technology, Pondicherry University, Puducherry - 605014, India

${ }^{2}$ Department of Chemistry, Kalasalingam University, Krishnankovil 626126, India

${ }^{3}$ Department of Chemistry, Sree Sakthi Engineering College, Coimbatore-641104, India

*E-mail: a.subramania@gmail.com nanoparticles based DSSC, which may be overcome by replacing the $\mathrm{ZnO}$ nanoparticles with 1D-ZnO nanostructures. ${ }^{21,22}$ These observations show both the shape of $\mathrm{ZnO}$ material and its interconnections strongly influence the way that electrons are made to transport through the DSSC photoanode. ${ }^{23}$

Thus, the structural control of $1 \mathrm{D}-\mathrm{ZnO}$ nanostructure having a well-defined shape is still an important goal for improving the power conversion efficiency of DSSC. Several efforts have been directed towards the synthesis of $1 \mathrm{D}-\mathrm{ZnO}$ nanostructures by various synthetic approaches. ${ }^{17,24}$ Among them, liquid phase synthesis is more facile and reproducible for producing nanostructures with compositional homogeneity. Most of these synthesis process requires high temperature and use of stabilizers/surfactants for morphological control which increases the reaction complexity and causes the impurity in the products. Solvothermal liquid-phase synthesis process has led to the simultaneous precipitation of suitable precursors in high-boiling alcohols, which has been proven to be a promising green chemical approach for practical significance. ${ }^{25}$ There have been reports on the synthesis of $\mathrm{ZnO}$ nanoparticles in different polyol media (ethylene glycol, diethylene glycol, 1,2-propanediol, etc. These polyol solvents act as complexing agent as well as a surfactant which adsorb on the surface of nanoparticles, thus preventing the aggregation of the nanoparticles.

We already demonstrated Polyvinylpyrrolidone(PVP) assisted solvothermal synthesis of nanostructured $\mathrm{MgO}$ and $\mathrm{TiO}_{2}$ using ethylene glycol. ${ }^{26,27}$ Here, ethylene glycol (EG) has been chosen to serve as a solvent as well as a reducing agent due to its relatively high boiling point $(\sim 197$ ${ }^{\circ} \mathrm{C}$ ) and high reducing capability. Besides, polyvinylpyrrolidone (PVP) was used exclusively as a capping agent. The power conversion efficiency of DSSC composed of the prepared $\mathrm{TiO}_{2}$ is nearly close to 
that of the same fabricated with std. $\mathrm{TiO}_{2}$ paste (Dye sol Ltd.) and higher than the same fabricated with $\mathrm{P} 25 \mathrm{TiO}_{2}$ (Degussa) based photoanode. ${ }^{27}$ These results have inspired to extend this PVP-assisted solvothermal process to prepare $\mathrm{ZnO}$ nanostructures for DSSC applications.

In the present investigation, we report an overall strategy of synthesizing $\mathrm{ZnO}$ nanoparticles and $\mathrm{ZnO}$ nanowires by a facile PVP assisted solvothermal process. The morphology, thermal behaviour and optical properties of the obtained $\mathrm{ZnO}$ nanostructures were investigated. Further, DSSCs were fabricated using $\mathrm{ZnO}$ nanoparticles and $\mathrm{ZnO}$ nanowires as photoanodes and their photovoltaic performances were studied in detail.

\section{Experimental details}

\subsection{Materials}

Zinc acetate $\left(\mathrm{Zn}\left(\mathrm{CH}_{3} \mathrm{COO}\right)_{2} \cdot 2 \mathrm{H}_{2} \mathrm{O}, 99.99 \%\right)$ and ethylene glycol (EG, $99.8 \%$ were procured from Sigma Aldrich. Polyvinylpyrrolidone (PVP, M. Wt. 130, 000) was purchased from AcrosOrganics. All the chemicals were used as received without further purification.

\subsection{Synthesis of $\mathrm{ZnO}$ nanoparticles and $\mathrm{ZnO}$ nanowires}

In the typical nanoparticles synthesis, $0.1 \mathrm{~mol}$ of zinc acetate was taken in a round bottom flask containing $100 \mathrm{~mL}$ of EG. To this, PVP was introduced at different mole concentrations $(0.001,0.002,0.003$, and 0.004 mol) with constant stirring to know the effect of various mole ratios of $\mathrm{Zn}$ (II)/PVP on nanoparticles formation. These solutions were refluxed at $195{ }^{\circ} \mathrm{C}$ for $3 \mathrm{~h}$. The precipitate was then collected by centrifugation. The residual PVP and EG were removed by washing with a copious amount of de-ionized water and ethanol. Finally, the precipitates were dried at $80{ }^{\circ} \mathrm{C}$ for $2 \mathrm{~h}$ under vacuum, followed by calcination at $350{ }^{\circ} \mathrm{C}$ for $2 \mathrm{~h}$ to obtain $\mathrm{ZnO}$ nanoparticles. $\mathrm{ZnO}$ nanowires were prepared by following the same procedure by dissolving $1 \mathrm{mmol}$ of zinc acetate and $0.2 \mathrm{mmol}$ of PVP in $100 \mathrm{~mL}$ of EG.

\subsection{Characterization}

The thermal behaviour of $\mathrm{ZnO}$ precursors was analyzed by thermogravimetry (TG) and differential thermal analysis (DTA) (Pyris Diamond, Perkin Elmer). The phase purity of the samples was evaluated by X-ray diffractometer (JEOL, Model: JDX) using nickelfiltered $\mathrm{Cu}-\mathrm{K}$ radiation between $10^{\circ}$ to $80^{\circ}$ at $2 \% \mathrm{~min}$.

Brunauer-Emmett-Teller (BET) method was used to calculate the specific surface area of $\mathrm{ZnO}$ nanostructures. The respective nitrogen adsorption isotherms were recorded at $77 \mathrm{~K}$ using a surface analyzer (Micromertics, Model: ASAP 2000).

The morphologies of $\mathrm{ZnO}$ nanostructures were investigated by using scanning electron microscope (JEOL, Model: JSM-840A, SEM) and High-resolution Transmission electron microscope (TEM) (Model: JEM 3010).

Photoluminescence (Model: Hitachi 850 fluorescence spectrophotometer) spectra of $\mathrm{ZnO}$ nanoparticles and $\mathrm{ZnO}$ nanowires were obtained using a Xe lamp $(150 \mathrm{~mW})$ as an excitation source at the excitation wavelength of $325 \mathrm{~nm}$ in between 350 and $600 \mathrm{~nm}$.

\subsection{Fabrication of DSSC}

The $\mathrm{ZnO}$ pastes were prepared by mixing $30 \mathrm{wt} . \%$ of prepared $\mathrm{ZnO}$ nanostructures, 15 wt.\% ethyl cellulose (binder), 50 wt.\% terpineol (solvent) and 5 wt.\% dibutyl phthalate (plasticizer) with intermittent sonication.

The prepared $\mathrm{ZnO}$ pastes were coated at the thickness of 10-12 $\mu \mathrm{m}$ on the cleaned FTO glass substrates by the doctor-blade method. They were then sintered in a muffle furnace at $450{ }^{\circ} \mathrm{C}$ for $30 \mathrm{~min}$ to obtain $\mathrm{ZnO}$ photoanodes. The active area was $0.20 \mathrm{~cm}^{2}$. The fabricated $\mathrm{ZnO}$ photoanodes were immersed in the N719 dye for $24 \mathrm{~h}$ and rinsed with pure ethanol to remove the excess of dye. The Pt counter electrodes were fabricated by sintering the std. Pt paste (Dyesol Ltd.) coated FTO glass plates at $450{ }^{\circ} \mathrm{C}$ for $30 \mathrm{~min}$. Finally, DSSCs were assembled by sandwiching each photoanodes and counter electrodes using thermal adhesive films (Surlyn, Dupont 1702, $60 \mu \mathrm{m}$-thick) by a hot press. The acetonitrile containing $0.5 \mathrm{M}$ 1-butyl-3-methylimidazolium iodide, 0.05 $\mathrm{M} \mathrm{I}_{2}, 0.5 \mathrm{M}$ LiI, and $0.5 \mathrm{M}$ 4-tert-butylpyridine as the electrolyte was injected through the holes and then sealed with small squares of surlyn strip. $^{28}$

\subsection{Photovoltaic performance of DSSC}

The photovoltaic performance of the assembled DSSCs based on $\mathrm{ZnO}$ nanowire and $\mathrm{ZnO}$ nanoparticles are analyzed using the solar simulator having light intensity of $100 \mathrm{~mW} / \mathrm{cm}^{2}$ (AM 1.5) integrated with computer-controlled digital source meter (Keithley, Model: 2420). Three DSSCs were fabricated for each system and their average photovoltaic values were taken. ${ }^{29}$

\section{Results and Discussion}

\subsection{TG/DTA analysis}

Fig. 1(a) shows the TG/DTA result of the $\mathrm{ZnO}$ precursor of nanoparticles (solid line) obtained using 0.1:0.002-mole ratio of $\mathrm{Zn}$ (II)/PVP. It is observed that the maximum weight loss occurs at about $330{ }^{\circ} \mathrm{C}$. In the DTA curve, the endothermic peak at $117{ }^{\circ} \mathrm{C}$ corresponds to $\sim 4.3 \%$ of mass loss due to the removal of physically adsorbed EG and water and the exothermic peak at $330{ }^{\circ} \mathrm{C}$ corresponds to $\sim 36.7 \%$ of mass loss due to the degradation of EG and organic groups. ${ }^{30}$ Further, there is no special mass loss observed from the above said temperature and the crystallization of the $\mathrm{ZnO}$ also starts at this temperature. Fig. 1(b) shows that there is no special difference in the mass loss of the $\mathrm{ZnO}$ precursor of nanowires in the first step from the TG and its corresponding endothermic peak in DTA curve (dashed line). From this figure, it is clearly seen that the exothermic peak corresponding to the degradation of EG and organic groups occurred at $322{ }^{\circ} \mathrm{C}$ in the DTA curve with the mass loss of $\sim 36.1 \%$ (dashed line).

\subsection{XRD studies}

The XRD patterns of $\mathrm{ZnO}$ products are obtained by calcination of

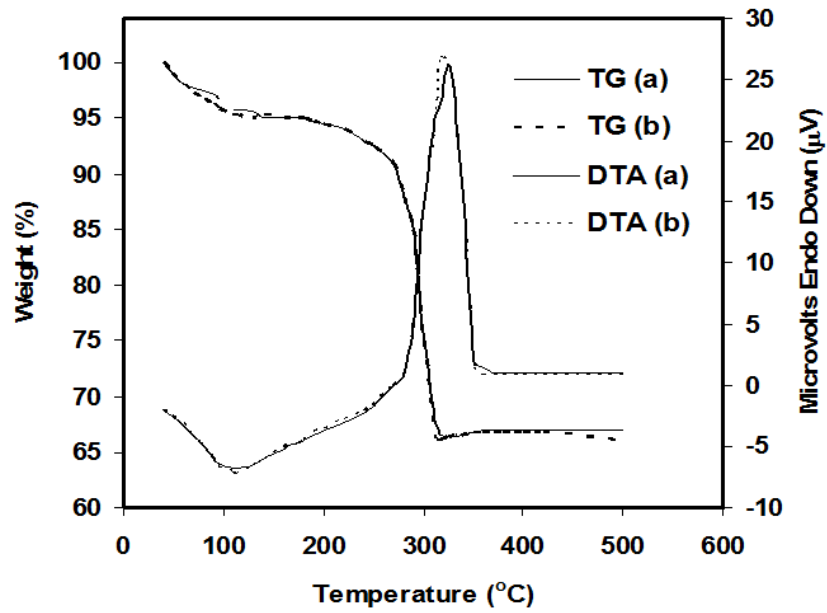

Fig. 1 TG/DTA curves of $\mathrm{ZnO}$ precursors of a) Nanoparticles (solid line) and b) Nanowires (dashed line). 
various mole ratio of $\mathrm{Zn}(\mathrm{II}) / \mathrm{PVP}$ precursors at $350{ }^{\circ} \mathrm{C}$. But only a representative XRD pattern for the mole ratio of 0.1/0.002 is shown in Fig. 2(a). This calcination temperature is quite consistent with the result of DTA. The high phase pure wurtzite $\mathrm{ZnO}$ nanoparticles with no impurity diffraction peaks are observed by calcinating the precursor sample at $500{ }^{\circ} \mathrm{C}$ for $2 \mathrm{~h}$ [Fig. 2(b)]. These diffraction patterns are well matched with the standard diffraction pattern of wurtzite-type $\mathrm{ZnO}$ (JCPDS card No.36-1451, a = 3.249 $\AA$, and $\mathrm{c}=5.026 \AA$ ). Their average particles size is calculated by using following Scherrer's formula and they are 14.6, 12.8, 47.0 and $81.0 \mathrm{~nm}$ respectively. The increase in the particle size at its higher concentration may be due to the adverse effect of the capping agent, as summarized in Table1.

The sharp diffraction peaks of the $\mathrm{ZnO}$ nanowires (Fig. 3) that are collected at the temperature of $500{ }^{\circ} \mathrm{C}$ for $2 \mathrm{~h}$ are well indexed to the JCPDS card No. 36-1451 of wurtzite-type $\mathrm{ZnO}$ structure with lattice constant values of $\mathrm{a}=3.249 \AA$ and $\mathrm{c}=5.026 \AA$.

\subsection{BET surface area analysis}

Table 1 summarizes the specific surface area of $\mathrm{ZnO}$ nanostructures. High surface area value of $121.2 \mathrm{~m}^{2} / \mathrm{g}$ is obtained for the PVP ratio of 0.002 mole than other concentrations. The marked difference in the surface area was attributed to the choice of the PVP content that altered the energetic of the solvothermal process.

\subsection{SEM and TEM studies}

SEM image confirms that the synthesized $\mathrm{ZnO}$ nanoparticles have single-phase primary particles as evident from Fig. 4(a). It shows that the $\mathrm{ZnO}$ nanoparticles obtained from the 0.1/0.002 mole ratio of $\mathrm{Zn}$ (II)/PVP calcined at $500{ }^{\circ} \mathrm{C}$ for $2 \mathrm{~h}$ are spherical in shape. The abnormal agglomeration of grains did not appear in the calcined product. The average diameter obtained from the SEM picture is less than $20 \mathrm{~nm}$. Some particles exhibited a diameter higher than $20 \mathrm{~nm}$. This may be due to the agglomeration of $\mathrm{ZnO}$ nanoparticles. The formation of $\mathrm{ZnO}$ nanoparticles is further confirmed by TEM studies.

The HR-TEM image confirms that $\mathrm{ZnO}$ nanoparticles obtained by calcinating the sample at $500{ }^{\circ} \mathrm{C}$ for $2 \mathrm{~h}$ are nearly spherical in shape of size $\sim 12 \mathrm{~nm}$ (Fig. 4(b)). Fig. 4(c) presents the lattice fringes with the spacings of 2.60 and 2.47 representing the (002) and (101) planes, respectively for hexagonal wurtzite $\mathrm{ZnO}$ nanoparticles. Fig. 4(d) shows the particles size histogram of prepared $\mathrm{ZnO}$ nanoparticles corresponding to the TEM image shown in Fig. 4(b). The size distribution was characterized by means of particle size of $\sim 12.5 \mathrm{~nm}$, relatively narrow distribution, although the size of some large particles is in the range between 12-16 $\mathrm{nm}$ as seen in the corresponding Fig. 4(d). The mean crystal size has a good relationship with the crystallite size (12.8 nm) obtained from the XRD pattern (Fig. 2). Eventually, PVP changes the properties of the polyol product. As the capping agent, it

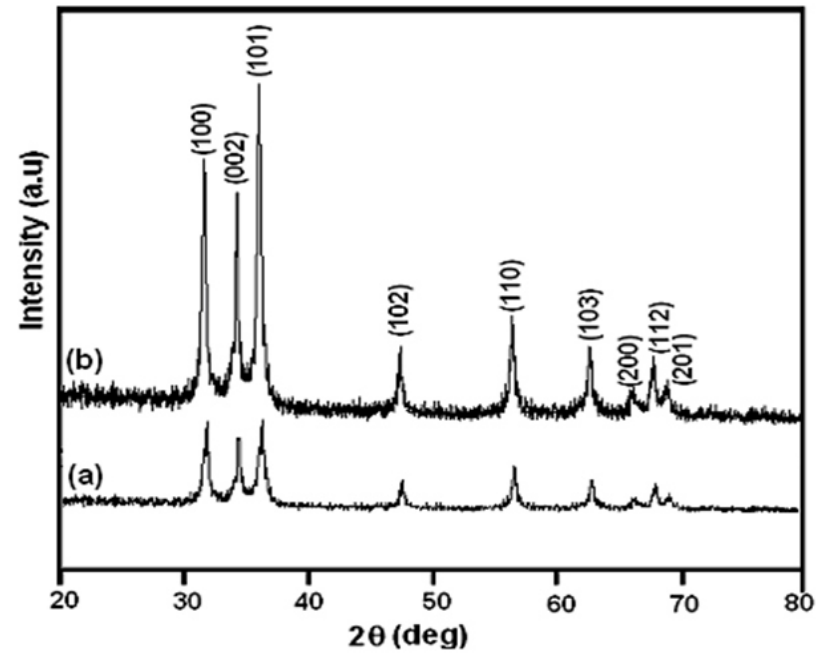

Fig. 2 XRD patterns of zinc oxide nanoparticles obtained by calcination of the precursor at (a) $350{ }^{\circ} \mathrm{C}$ and (b) $500{ }^{\circ} \mathrm{C}$ for $2 \mathrm{~h}$.

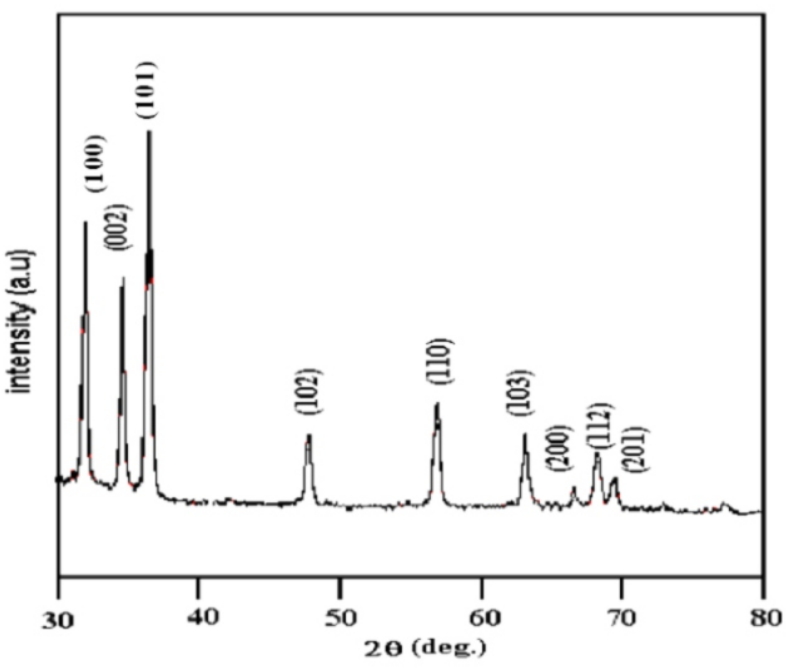

Fig. 3. XRD pattern of $\mathrm{ZnO}$ nanowires at $500{ }^{\circ} \mathrm{C}$ for $2 \mathrm{~h}$.

Table1. The specific surface area and particles size of the prepared $\mathrm{ZnO}$ products obtained from the solvothermal process.

\begin{tabular}{ccccc}
\hline \multicolumn{2}{c}{ Mole ratio } & & Specific surface area \\
$\mathrm{Zn}\left(\mathrm{CH}_{3} \mathrm{COO}\right)_{2}$ & $\mathrm{PVP}$ & $\left(\mathrm{m}^{2} / \mathrm{g}\right)^{\mathrm{a}}$ & $\begin{array}{c}\text { Crystallite size } \\
(\mathrm{nm})^{\mathrm{b}}\end{array}$ & $\begin{array}{c}\text { Particles size } \\
(\mathrm{nm})^{\mathrm{c}}\end{array}$ \\
\hline 0.1 & 0.001 & 91 & 14.6 & 14.8 \\
0.1 & 0.002 & 121 & 12.8 & 42.5 \\
0.1 & 0.003 & 71 & 47.2 & 81.0 \\
0.1 & 0.004 & 53 & 81.3 & 81.0 \\
\hline
\end{tabular}

${ }^{\mathrm{a}}$ From BET analysis; ${ }^{\mathrm{b}}$ From XRD Scherrer's formula; ${ }^{\mathrm{c}}$ From TEM analysis. 
reduces the particles size in the nanoscale without any agglomeration in the prepared $\mathrm{ZnO}$ product.

As seen in Fig. 5(a\&b), the $\mathrm{ZnO}$ nanowires exhibited 1D nanostructure with no amorphous layer at the starting to end tip of the wires. From the SEM image Fig. 5 (a), it is found that the diameter and length of the $\mathrm{ZnO}$ nanowires obtained are 10-30 nm (average diameter $\sim 22 \mathrm{~nm}$ ) and $20 \mu \mathrm{m}$, respectively. TEM image Fig. 5(b) clearly designates that $\mathrm{ZnO}$ nanowires have a uniform width along their entire length. Fig. 5(c) shows the lattice fringes with a spacing of $0.519 \mathrm{~nm}$ and the arrow indicating the growing direction. The inset Fig.5 (d) shows the selected-area electron diffraction (SAED) pattern confirming the lattice spacing and the $c$ axis [0001] of the single-crystalline $\mathrm{ZnO}$ nanowires. However, the $\mathrm{ZnO}$ nanowires become shorter (data not shown here) and transformed into bulk $\mathrm{ZnO}$ structure upon calcination at $600{ }^{\circ} \mathrm{C}$ for $2 \mathrm{~h}$.

\subsection{Photoluminescence spectra}

The photoluminescence spectra (Fig. 6) show that $\mathrm{ZnO}$ nanoparticles and nanowires exhibited UV emission at $382 \mathrm{~nm}$ and $380 \mathrm{~nm}$, respectively, implying their wide band gap. The green light emission observed at $520 \mathrm{~nm}$ and $517 \mathrm{~nm}$, respectively, is attributed to the presence of ionized oxygen vacancy. The recombination of this oxygen vacancy with the photogenerated hole causes the green emission. ${ }^{31}$

As evident from the SEM and HR-TEM images, the morphology of wurtzite $\mathrm{ZnO}$ nanostructure is changed with changing in the molar concentrations of $\mathrm{Zn}$ (II)/PVP. The zinc acetate precursor solution at 0.1 mole yields spherical morphology, whereas, the 0.002-mole results in wire like morphology. This demonstrated that the average diameter of $\mathrm{ZnO}$ nanowires strongly depends on the precursor concentration. Further, as the capping agent, PVP influences the nucleation kinetics and subsequent growth. At higher concentration, the presence of PVP
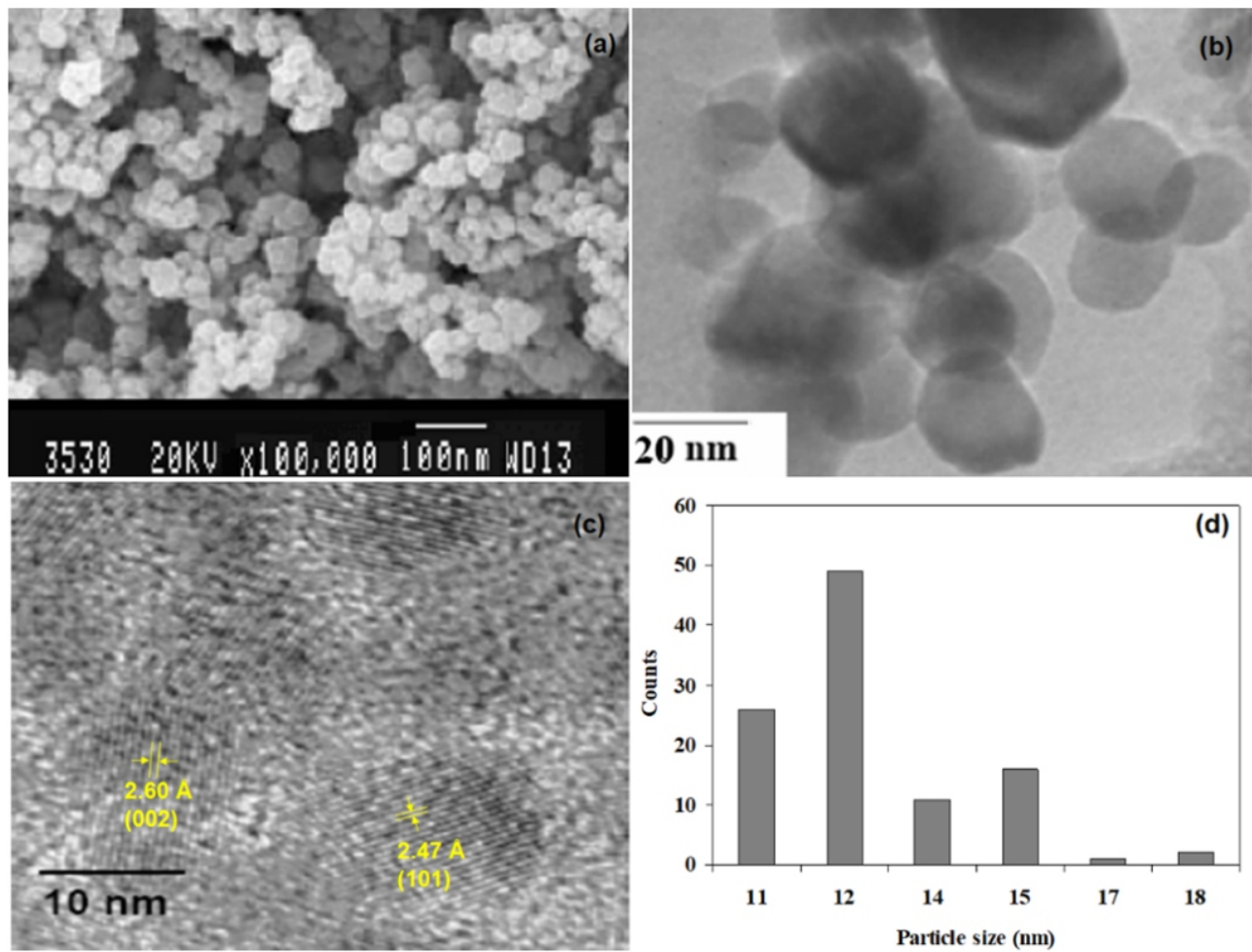

Fig. 4 (a) SEM image; (b) TEM image; (c) HR-TEM image; (d) Particles size histogram of ZnO nanoparticles obtained from the solvothermal process.
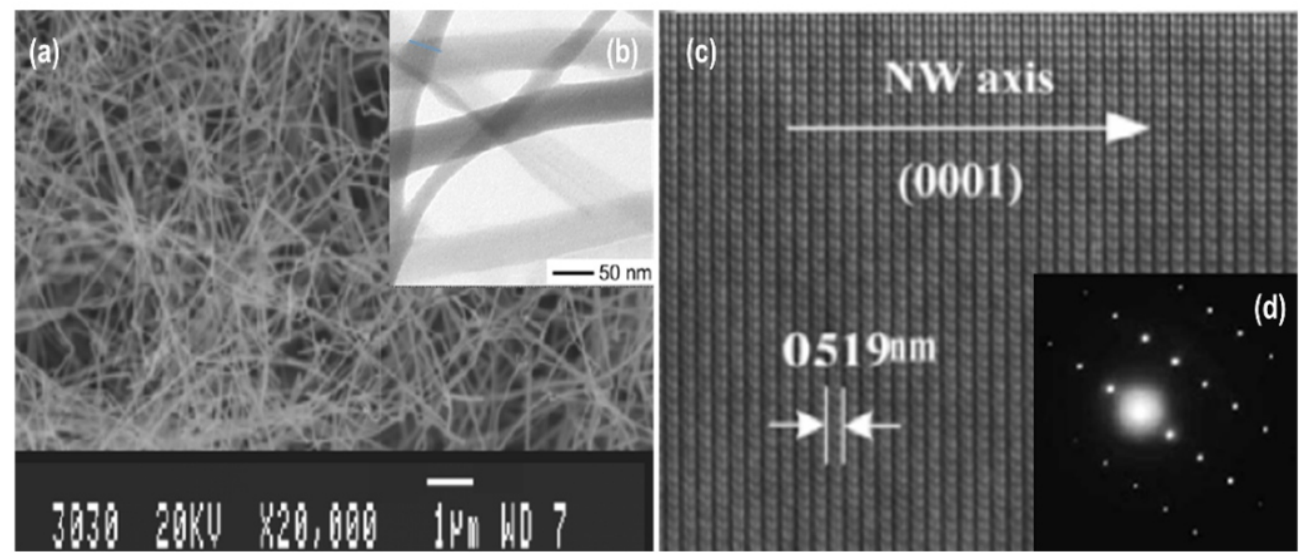

Fig. 5 (a) SEM image; (b) HR-TEM image; (c) HR-TEM image; (d) Selected-area electron diffraction (SAED) pattern of ZnO nanowires obtained from the solvothermal process. 
slows down the growth of larger particles, whereas the growth remains almost same for small particles. Thus, the PVP plays a critical role in obtaining nanoparticles of uniform size and shape. However, the interaction between the PVP molecules become more significant at lower molar concentration. This favours the formation of nanowires with controlled length and diameter.

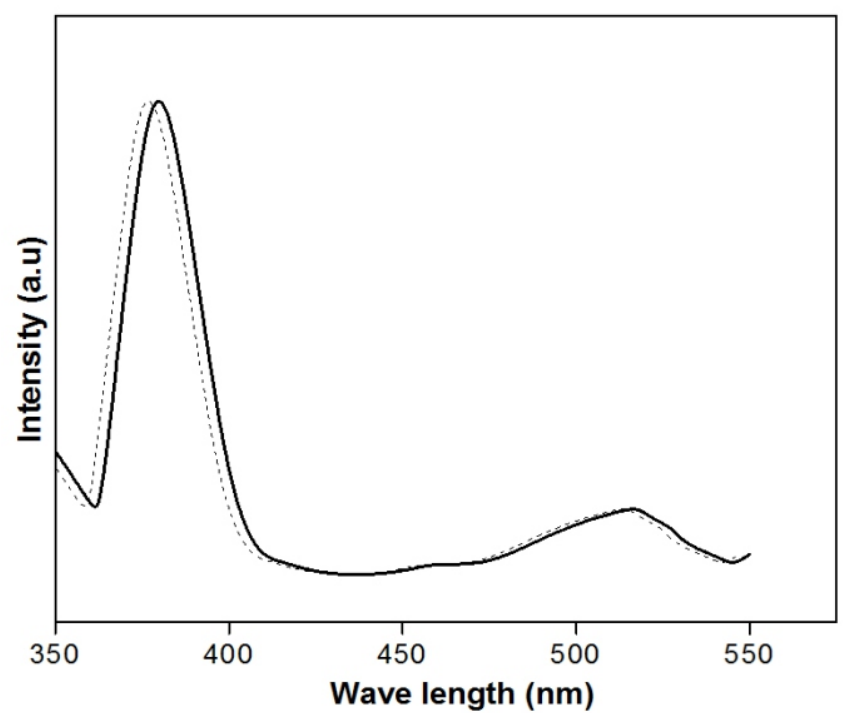

Fig. 6 Photoluminescence spectra of $\mathrm{ZnO}$ nanoparticles (solid line) and $\mathrm{ZnO}$ nanowires (dashed line).

\subsection{Photovoltaic performance studies}

Fig. 7 shows the photocurrent density-voltage (J-V) curves of DSSCs fabricated with $\mathrm{ZnO}$ nanowires and $\mathrm{ZnO}$ nanoparticles based photoanodes and their corresponding parameters are given in Table 2. It shows that the DSSC fabricated using $\mathrm{ZnO}$ nanowires as the photoanode exhibits the PCE of $1.81 \%$ which is higher than that

Table 2 Photovoltaic parameters of DSSCs fabricated with (a) ZnO nanowires and (b) ZnO nanoparticles based photoanodes.

\begin{tabular}{lcccc}
\hline Photoanode & $\begin{array}{c}\mathbf{V}_{\text {oc }} \\
(\mathbf{V})\end{array}$ & $\begin{array}{c}\mathbf{J}_{\text {sc }} \\
\left(\mathbf{m A . c m} \mathbf{c m}^{-2}\right)\end{array}$ & FF & $\begin{array}{c}\boldsymbol{\eta} \\
(\mathbf{\%})\end{array}$ \\
\hline ZnO Nanoparticles & 0.55 & 4.31 & 0.475 & 1.13 \\
ZnO Nanowires & 0.58 & 6.64 & 0.469 & 1.81 \\
\hline
\end{tabular}
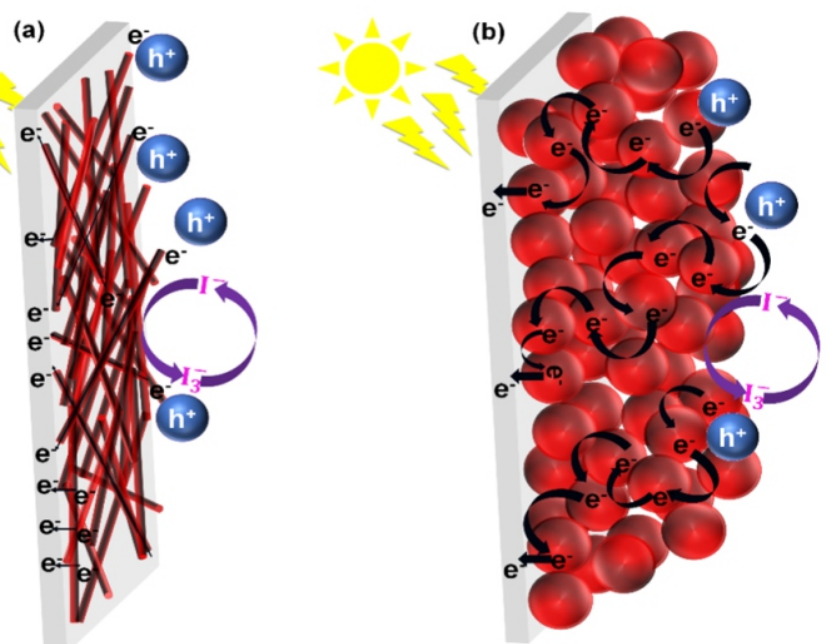

Fig. 8 Schematic illustration of photo-excited electrons transport in (a) ZnO Nanowires and (b) ZnO Nanoparticles based photoanodes. 
Table 3 Comparison of photovoltaic performanceof DSSC based on prepared ZnO nanowires with reported ZnO nanowires based DSSCs.

\begin{tabular}{cllll}
\hline S.No. & Photoanode & Synthesis method & PCE (\%) & Ref. \\
\hline 1. & ZnO Nanowires & Microwave - assisted hydrothermal method & 1.55 & 34 \\
2. & ZnO Nanowires & Chemical solution method & 0.812 & 35 \\
3. & ZnO Nanowires & Chemical solution method & 1.52 & 36 \\
4. & ZnO Nanowires & Chemical solution method & 1.49 & 37 \\
5. & ZnO Nanowires & Chemical solution method & 1.45 & 38 \\
6. & ZnO Nanowires & PVP assisted solvothermal method & 1.81 & This work \\
\hline
\end{tabular}

fabricated using the $\mathrm{ZnO}$ nanoparticles-based photoanode $(1.13 \%)$. This is due to electron hopping events that limit electron transport in the case of $\mathrm{ZnO}$ nanoparticles based photoanode. The prepared $\mathrm{ZnO}$ nanowires exhibited superior PCE than the other reported $\mathrm{ZnO}$ nanowires (Table 3).

The possibility of grain boundary between the nanoparticles reduced the chemical potential (or charge transport energy) contact which makes the time delayed charge transport via hopping events along the nanoparticles. But, in the case of $\mathrm{ZnO}$ nanowires, the continuum chemical potential contact (due to the absence of grain boundaries) leads to chemically driven carrier transport which can be explained by unified Einstein's diffusion-mobility model. ${ }^{32}$ Here, the electron transport enhancement in $\mathrm{ZnO}$ nanowires swiftly allows the photogenerated electrons before the recombination started. ${ }^{33}$ Hence, the electron transfer rate in the $\mathrm{ZnO}$ nanowires is higher than $\mathrm{ZnO}$ nanoparticles which are schematically illustrated in Fig. 8. This allows a higher photocurrent $\left(\mathrm{J}_{\mathrm{sc}}\right)$ with an improved photoconversion efficiency for the DSSC fabricated with $\mathrm{ZnO}$ nanowires based photoanode.

\section{Conclusion}

High phase pure wurtzite $\mathrm{ZnO}$ nanoparticles and $\mathrm{ZnO}$ nanowires were successfully prepared by PVP assisted solvothermal process. During the thermal decomposition of the precursor, crystallization started at $330{ }^{\circ} \mathrm{C}$ and a well-defined polycrystalline powder was obtained at $500{ }^{\circ} \mathrm{C}$ for $2 \mathrm{~h}$. Especially, $\mathrm{ZnO}$ nanoparticles have a crystallite size of $12-16 \mathrm{~nm}$ and its average surface area was $121.2 \mathrm{~m}^{2} / \mathrm{g}$. The change in morphology and size of the $\mathrm{ZnO}$ were examined under various $\mathrm{Zn}(\mathrm{II}) / \mathrm{PVP}$ mole ratio and addressed in the present study. The characteristic UV emission at 382 and $380 \mathrm{~nm}$ and a green emission at 520 and $517 \mathrm{~nm}$ were observed for the prepared $\mathrm{ZnO}$ nanoparticles and $\mathrm{ZnO}$ nanowires, respectively. The highest PCE of $1.81 \%$ was achieved for DSSC fabricated using $\mathrm{ZnO}$ nanowires as photoanode than that of $\mathrm{ZnO}$ nanoparticles based photoanode $(1.13 \%)$. This is due to the better electron mobility offered by $\mathrm{ZnO}$ nanowires.

\section{Acknowledgments}

One of the authors, Dr.AS gratefully acknowledge the Council of Scientific and Industrial Research (CSIR), New Delhi (Ref. No.01/2810/14/EMR-II) for the financial support. Mr. MV grateful to the Department of Science and Technology (DST), New Delhi for providing a fellowship under DST-Inspire Award (IF160290).

\section{Conflict of Interest}

The authors declare no conflict of interest.

\section{References}

1. V. Murugadoss, N. Wang, S. Tadakamalla, B. Wang, Z. Guo and S. Angaiah, J. Mater. Chem. A, 2017, 5, 14583-14594.

2. V. Elayappan, V. Murugadoss, S. Angaiah, Z. Fei and P. Dyson, J. Appl. Polym. Sci., 2015, 132 (45), 42777.

3. T. Liu, K. Yu, L. Gao, H. Chen, N. Wang, L. Hao, T. Li, H. He and Z. Guo, J. Mater. Chem. A, 2017, 5 (34), 17848-17855.

4. S. Angaiah, V. Murugadoss, S. Arunachalam, P. Panneerselvam and S. Krishnan, Eng. Sci., 2018, 4, 44-51.

5. V. Murugadoss, S. Arunachalam, V. Elayappan and S. Angaiah, Ionics, 2018, 24 (12), 4071-4080

6. Z. Salam, E. Vijayakumar, A. Subramania, N. Sivasankar and S. Mallick, Sol. Energy. Mater. Sol. Cells, 2015, 143, 250-259.

7. G. R. A. Kumara, U. Deshapriya, C. S. K. Ranasinghe, E. N. Jayaweera and R. M. G. Rajapakse, J. Semicond., 2017, 39 (3), 033005-033005-6.

8. I. Y. Y. Bu, Optik, 2018, 157, 406-409.

9. Z. Li, D. Bi, Y. Zhao, R. Liu and J. Ye; Y. Zhou, Electrochim. Acta, 2018, 262, 124-134.

10. S. Chappel and A. Zaban, Sol. Energy Mater. Sol. Cells, 2002, 71 (2), 141152

11. U. V. Desai, C. Xu, J. Wu and D. Gao, J. Phys. Chem. C, 2013, 117 (7), 3232-3239.

12. C. Justin Raj, S. N. Karthick, K. V. Hemalatha, S. K. Kim, B. C. Kim, K. H. Yu and H. J. Kim, Appl. Phys. A, 2014, 116 (2), 811-816.

13. N. Singh, V. Murugadoss, S. Nemala, S. Mallick and S. Angaiah, Solar Energy, 2018, 171, 571-579.

14. J. Burschka, N. Pellet, S. J. Moon, R. Humphry-Baker, P. Gao, M. K Nazeeruddin and M. Gratzel, Nature, 2013, 499, 316

15. L. Yang, X. Wang, X. Mai, T. Wang, C. Wang, X. Li, V. Murugadoss, Q. Shao, S. Angaiah and Z. Guo, J. Colloid Interface Sci., 2019, 534, 459-468.

16. Y. H. Sung, W. P. Liao, D. W. Chen, C. T. Wu, G. J. Chang and J. J. Wu, Adv. Funct. Mater, 2012, 22 (18), 3808-3814.

17. X. Yin, W. Que, D. Fei, H. Xie, Z. He and G. Wang, Electrochim. Acta, 2013, 89, 561-570.

18. Y. X. Wang, Z. C. Shen, D. D. Huang and Z. S. Yang, Mater. Lett., 2018, 214, 88-90.

19. Z. Huang, Y. Dou, K. Wan, F. Wu, L. Fang, H. Ruan, B. Hu, F. Meng and M. Liao, J. Mater. Sci.: Mater. Electron., 2017, 28 (23), 17414-17420.

20. N. Singh, Z. Salam, N. Sivasankar and A. Subramania, Mater. Sci. Semicond. Process., 2017, 64 (Complete), 16-23.

21. A. B. F. Martinson, J. E. McGarrah, M. O. K. Parpia and J. T. Hupp, Phys. Chem. Chem. Phys., 2006, 8 (40), 4655-4659.

22. N. Kopidakis, K. D. Benkstein, J. van de Lagemaat and A. J. Frank, J. Phys. Chem. B, 2003, 107 (41), 11307-11315.

23. Y. F. Wang, W. X. Zhao, X. F. Li and D. J. Li, Electrochim. Acta, 2015, 151, 399-406.

24. S. B. Rawal, S. D. Sung, S. Y. Moon, Y. J. Shin and W. I. Lee, Mater. Lett., 2012, 82 (Complete), 240-243.

25. N. V. Long, Y. Yang, C. M. Thi, L. H. Phuc and M. Nogami, J. Electron. Mater., 2017, 46 (6), 3615-3621.

26. A. Subramania, G. V. Kumar, A. R. S. Priya and T. Vasudevan, 
Nanotechnology, 2007, 18 (22), 225601.

27. P. Pratheep, E. Vijayakumar and A. Subramania, Appl. Phys. A, 2015, 119 (2), 497-502.

28. V. Elayappan, P. Panneerselvam, S. Nemala, K. S. Nallathambi and S. Angaiah, Appl. Phys. A, 2015, 120 (3), 1211-1218.

29. P. Panneerselvam, V. Murugadoss, V. Elayappan, N. Lu, Z. Guo and S. Angaiah, ES Energy Environ., 2018, 1, 99-105.

30. M. Popa and M. Kakihana, Solid State Ionics, 2002, 151 (1), 251-257.

31. E. M. Wong and P. C. Searson, Appl. Phys. Lett., 1999, 74 (20), 2939-2941.

32. K. Navamani and S. K. Pati, arXiv:1705.03616 [cond-mat.other] 2018.

33. C. Roger, I. Kemakorn and K. Ilona, AIMS Mater. Sci., 2016, 3 (1), 51-65.
34. H. Guo, R. Ding, N. Li, K. Hong, L. Liu and H. Zhang, Physica E: Lowdimensional Systems and Nanostructures 2019, 105, 156-161.

35. F. A. Mahmoud and N. Ahmed, J. Semicond., 2018, 39 (9), 093002.

36. M. Wang and Y. Wang, J. Mater. Sci. Eng., 2011, 1 (1), 1000101.

37. M. C. Kao, H. Z. Chen, S. L. Young, C. C. Lin and C. Y. Kung, Nanoscale Res. Lett., 2012, 7 (1), 260.

38. L. Etgar, J. S. Bendall, V. Laporte, M. E. Welland and M. Graetzel, J. Mater. Chem., 2012, 22 (46), 24463-24468.

Publisher's Note Engineered Science Publisher remains neutral with regard to jurisdictional claims in published maps and institutional affiliations. 